\title{
Vasoinhibins May Contribute to Postpartum Depression
}

\author{
Jakob Triebel'*, Gonzalo Martínez de la Escalera², Carmen Clapp ${ }^{2}$ and Thomas Bertsch ${ }^{1}$ \\ ${ }^{1}$ Laboratory Medicine and Transfusion Medicine, Institute for Clinical Chemistry, Nuremberg General Hospital, Paracelsus \\ Medical University, Nuremberg, Germany, ${ }^{2}$ Instituto de Neurobiología, Universidad Nacional Autónoma de México (UNAM), \\ Querétaro, México
}

Keywords: vasoinhibins, prolactin/vasoinhibin axis, postpartum depression, 16K prolactin, prolactin

The Diagnostic and Statistical Manual of Mental Disorders lists the peripartum period as an onset specifier for major depressive disorder, where "peripartum period" is defined as the time of the "most recent episode during pregnancy as well as 4 weeks following delivery" (1). In a recent article, Rosman et al. reported that patients suffering from peripartum cardiomyopathy (PPCM) demonstrated a particularly high prevalence of depression, compared to healthy females of similar age, postpartum women, and other heart failure patients (2). "Peripartum cardiomyopathy is an idiopathic cardiomyopathy presenting with heart failure secondary to left ventricular systolic dysfunction toward the end of pregnancy or in the month following delivery, where no other cause of heart failure is found" (3). PPCM is relatively rare. The incidence for PPCM was reported to be 1 per 968 live births in the United States (4), and 1 per 10,149 in Denmark, respectively (5). As mentioned, the disease is idiopathic, meaning that no specific causal mechanism is known. However, a seminal study in 2007 reported that a $16 \mathrm{kDa}$ vasoinhibin isoform may be a causal factor in the development of PPCM (6). Vasoinhibins inhibit the proliferation, permeability, and dilation of blood vessels and are generated

OPEN ACCESS

Edited by: Gianluca Serafini,

University of Genoa, Italy

Reviewed by:

Aikaterini Arvaniti,

Democritus University of

Thrace, Greece

${ }^{*}$ Correspondence:

Jakob Triebel

jakob.triebe/@gmx.de

Specialty section:

This article was submitted to Mood and Anxiety Disorders,

a section of the journal

Frontiers in Psychiatry

Received: 27 June 2017 Accepted: 25 August 2017 Published: 12 September 2017

Citation:

Triebel J, Martínez de la Escalera G, Clapp C and Bertsch T (2017) Vasoinhibins May Contribute to Postpartum Depression.

Front. Psychiatry 8:167. doi: 10.3389/fpsyt.2017.00167 by the proteolytic cleavage of their precursor molecule prolactin (PRL), the pituitary hormone colloquially referred to as the "nursing hormone" $(7,8)$. PRL increases during pregnancy in preparation for lactation and remains elevated during the postpartum period in the nursing mothers (9). It has been suggested that in PPCM, the $16 \mathrm{kDa}$ vasoinhibin isoform is excessively generated and exerts a detrimental effect on the microvascularization of the myocardium, resulting in left ventricular dysfunction. Elevated circulating vasoinhibin levels have been demonstrated in patients with PPCM (6). A clinical trial investigating bromocriptine effectiveness to suppress vasoinhibin generation in patients with PPCM is underway (10) (www.clinicaltrials.gov; identifier: NCT00998556).

Women with PPCM may have an inherently higher risk for depression due to the prognostic uncertainty associated with PPCM, as argued by Rosman et al. (2). Also, genetic and non-endocrine factors may contribute to the complex etiopathology of postpartum depression (11-13). However, due to the profound hormonal changes during pregnancy and postpartum, endocrine factors have been often investigated as additional contributors to postpartum depression etiopathology $(14,15)$. Interestingly, not only have vasoinhibins been reported to be causally linked to PPCM but also to induce anxiety- and depression-related behaviors (16). After the intraventricular administration of vasoinhibins, rats exhibit increased anxiety and depression when subjected to the open field test, the forced swim test, or the elevated plus-maze; and vasoinhibins have direct effects on neuronal function (17). Moreover, vasoinhibin plasma levels are elevated in normal human pregnancy (18) and appear further elevated in patients with PPCM (6). A likely consequence is a surge of vasoinhibins in the cerebrospinal fluid (CSF). This is because PRL is a normal constituent of CSF and CSF PRL levels are a function of plasma PRL levels $(19,20)$, and elevation of circulating PRL levels leads to the accumulation of vasoinhibins across the retinal blood barrier. Along this line, it can be speculated that elevated vasoinhibins in the CSF of peripartum women, and even more so in those with PPCM, may contribute to the development of postpartum depression.

The high prevalence of postpartum depression in patients with PPCM reported by Rosman et al. (2), the causative role of vasoinhibins in PPCM (6), the elevated circulating levels of vasoinhibins 
in patients with PPCM (6), and the anxiogenic and depressive properties of vasoinhibins (16) highlight the need for investigating the contribution of vasoinhibins to postpartum depression and the putative value of their circulating levels as risk factors for this condition.

\section{REFERENCES}

1. APA. Diagnostic and Statistical Manual of Mental Disorders. 5th ed. Arlington, VA: American Psychiatric Association (2013).

2. Rosman L, Salmoirago-Blotcher E, Cahill J, Wuensch KL, Sears SF. Depression and health behaviors in women with peripartum cardiomyopathy. Heart Lung (2017) 46(5):363-8. doi:10.1016/j.hrtlng.2017.05.004

3. Sliwa K, Hilfiker-Kleiner D, Petrie MC, Mebazaa A, Pieske B, Buchmann E. Current state of knowledge on aetiology, diagnosis, management, and therapy of peripartum cardiomyopathy: a position statement from the Heart Failure Association of the European Society of Cardiology Working Group on peripartum cardiomyopathy. Eur J Heart Fail (2010) 12(8):767-78. doi:10.1093/ eurjhf/hfq120

4. Kolte D, Khera S, Aronow WS, Palaniswamy C, Mujib M, Ahn C, et al. Temporal trends in incidence and outcomes of peripartum cardiomyopathy in the United States: a nationwide population-based study. J Am Heart Assoc (2014) 3(3):e001056. doi:10.1161/JAHA.114.001056

5. Ersboll AS, Johansen M, Damm P, Rasmussen S, Vejlstrup NG, Gustafsson F. Peripartum cardiomyopathy in Denmark: a retrospective, population-based study of incidence, management and outcome. Eur J Heart Fail (2017). doi:10.1002/ejhf.882

6. Hilfiker-Kleiner D, Kaminski K, Podewski E, Bonda T, Schaefer A, Sliwa K, et al. A cathepsin D-cleaved $16 \mathrm{kDa}$ form of prolactin mediates postpartum cardiomyopathy. Cell (2007) 128(3):589-600. doi:10.1016/j.cell.2006.12.036

7. Clapp C, Thebault S, Macotela Y, Moreno-Carranza B, Triebel J, Martinez de la Escalera G. Regulation of blood vessels by prolactin and vasoinhibins. Adv Exp Med Biol (2015) 846:83-95. doi:10.1007/978-3-319-12114-7_4

8. Triebel J, Bertsch T, Bollheimer C, Rios-Barrera D, Pearce CF, Hufner M, et al. Principles of the prolactin/vasoinhibin axis. Am J Physiol Regul Integr Comp Physiol (2015) 309(10):R1193-203. doi:10.1152/ajpregu.00256.2015

9. Tyson JE, Hwang P, Guyda H, Friesen HG. Studies of prolactin secretion in human pregnancy. Am JObstet Gynecol (1972) 113(1):14-20. doi:10.1016/0002-9378(72)90446-2

10. Haghikia A, Podewski E, Berliner D, Sonnenschein K, Fischer D, Angermann CE, et al. Rationale and design of a randomized, controlled multicentre clinical trial to evaluate the effect of bromocriptine on left ventricular function in women with peripartum cardiomyopathy. Clin Res Cardiol (2015) 104(11):911-7. doi:10.1007/s00392-015-0869-5

11. Arany Z, Elkayam U. Peripartum cardiomyopathy. Circulation (2016) 133(14): 1397-409. doi:10.1161/CIRCULATIONAHA.115.020491

\section{AUTHOR CONTRIBUTIONS}

JT wrote the manuscript. GE, CC, and TB edited and revised the manuscript. All authors approved the final version of the manuscript.

12. Treloar SA, Martin NG, Bucholz KK, Madden PA, Heath AC. Genetic influences on post-natal depressive symptoms: findings from an Australian twin sample. Psychol Med (1999) 29(3):645-54. doi:10.1017/S0033291799008387

13. Viktorin A, Meltzer-Brody S, Kuja-Halkola R, Sullivan PF, Landen M, Lichtenstein P, et al. Heritability of perinatal depression and genetic overlap with nonperinatal depression. Am J Psychiatry (2016) 173(2):158-65. doi:10.1176/appi.ajp.2015.15010085

14. Bloch M, Daly RC, Rubinow DR. Endocrine factors in the etiology of postpartum depression. Compr Psychiatry (2003) 44(3):234-46. doi:10.1016/S0010 440X(03)00034-8

15. Groer MW, Morgan K. Immune, health and endocrine characteristics of depressed postpartum mothers. Psychoneuroendocrinology (2007) 32(2): 133-9. doi:10.1016/j.psyneuen.2006.11.007

16. Zamorano M, Ledesma-Colunga MG, Adan N, Vera-Massieu C, Lemini M, Mendez I, et al. Prolactin-derived vasoinhibins increase anxiety- and depression-related behaviors. Psychoneuroendocrinology (2014) 44:123-32. doi:10.1016/j.psyneuen.2014.03.006

17. Castillo X, Melo Z, Varela-Echavarria A, Tamariz E, Arona RM, Arnold E, et al. Vasoinhibin suppresses the neurotrophic effects of VEGF and NGF in newborn rat primary sensory neurons. Neuroendocrinology (2017). doi:10.1159/ 000477768

18. Sinha YN, Gilligan TA, Lee DW, Hollingsworth D, Markoff E. Cleaved prolactin: evidence for its occurrence in human pituitary gland and plasma. J Clin Endocrinol Metab (1985) 60(2):239-43. doi:10.1210/jcem-60-2-239

19. Assies J, Schellekens AP, Touber JL. Prolactin in human cerebrospinal fluid. J Clin Endocrinol Metab (1978) 46(4):576-86. doi:10.1210/jcem-46-4-576

20. Barreca T, Perria C, Franceschini R, Siani C, Messina V, Francaviglia N, et al. Diurnal prolactin changes in human cerebrospinal fluid. Clin Endocrinol (Oxf) (1984) 20(6):649-55. doi:10.1111/j.1365-2265.1984.tb00115.x

Conflict of Interest Statement: The authors declare that the research was conducted in the absence of any commercial or financial relationships that could be construed as a potential conflict of interest.

Copyright (C) 2017 Triebel, Martínez de la Escalera, Clapp and Bertsch. This is an openaccess article distributed under the terms of the Creative Commons Attribution License (CC BY). The use, distribution or reproduction in other forums is permitted, provided the original author(s) or licensor are credited and that the original publication in this journal is cited, in accordance with accepted academic practice. No use, distribution or reproduction is permitted which does not comply with these terms. 